\title{
What is not so Cool about US-COOL Regulations? A critical analysis of the Appellate Body's ruling on US-COOL
}

\author{
PETROS C. MAVROIDIS* \\ EUI, Florence \\ KAMAL SAGGI \\ Vanderbilt University
}

\begin{abstract}
In US-COOL, the Appellate Body (AB) of the World Trade Organization (WTO) found that the US measure imposing country of origin labelling (COOL) requirements on livestock of domestic, foreign, and mixed origin was in violation of the obligation to avoid discrimination embedded in Article 2.1 of the WTO Agreement on Technical Barriers to Trade (TBT). We argue that the $\mathrm{AB}$ could not and should not have reached this decision based on the information available to it. The $\mathrm{AB}$ adopted an erroneous methodology: under its view, the consistency of a measure coming under the purview of the TBT can be examined under Article 2.1 irrespective of its evaluation under Article 2.2 thereby making the two obligations distinct. The $\mathrm{AB}$ also failed to address the central question raised by this dispute: Does there exist an alternative to COOL that is less trade restrictive? We argue that the over-arching issue in this case should have been to determine what, if anything, the TBT Agreement did to alter or enhance the obligation of non-discrimination that was already embedded in the arsenal of the multilateral trading rules. Unless the $\mathrm{AB}$ asks this question in subsequent case law pertaining to the TBT, we risk seeing repetitions of similar mistakes in the future.
\end{abstract}

\section{The Facts of US-COOL}

Up until 2011, EC-Sardines was the only dispute that could qualify as a 'core TBT dispute'. While claims under the WTO Agreement on Technical Barriers to Trade (TBT Agreement) had been raised in numerous other disputes that came under the aegis of General Agreement on Tariffs and Trade (GATT), these claims were typically of a peripheral nature as opposed to being at the core of such disputes ${ }^{1}$. EC-Sardines dealt with some of the key provisions of the

\footnotetext{
* Email: Petros.Mavroidis@unine.ch

We are highly indebted to Carlo-Maria Cantore, Aaron Cosbey, Bernard M. Hoekman, Rob Howse, Phil Levy, Juan-Alberto Marchetti, and Alan O. Sykes for helpful discussions.

1 Horn et al. (2011).
} 
TBT Agreement ${ }^{2}$, while leaving some important questions (such as the understanding of the necessity and the non-discrimination disciplines in the TBT Agreement) totally un-interpreted. In 2011, three cases were adjudicated almost simultaneously: US-Clove Cigarettes; US-Tuna II (Mexico); and, US-COOL. The scope of these disputes was more comprehensive than that of EC-Sardines, and WTO adjudicating bodies had to deal with almost all key provisions appearing in the TBT Agreement ${ }^{3}$. The three Panel reports adopted irreconcilable approaches with respect to the interpretation of key terms such as 'like products'. ${ }^{4}$ As a result, the task of the Appellate Body (AB) became quite demanding. At the same time, however, US-COOL was a good opportunity for the AB to establish a coherent test for consistency with the TBT Agreement. Alas, it seems to have failed to take advantage of this opportunity. In this paper we argue this position by critically evaluating the $\mathrm{AB}$ report on US-COOL, a dispute filed by Canada and Mexico challenging certain recent US regulations concerning the labelling of meat products. 5

Via the 2008 Farm Bill, the US adopted legislation (i.e. a technical regulation) aimed at informing consumers about the origin of meat products, and to this effect imposed labelling requirements that distinguished four categories of meat products, two of which referred to meat products wholly obtained from (i.e. born, raised, and slaughtered) within the US (category A) or abroad (category D), and two others that covered meat products originating in more than one country (categories B and C, which cover meat obtained from a cow say raised in Mexico, and slaughtered in the US). While both labels B and C indicate multiple sources of origin, there is an important distinction between them: meat sold under label $\mathrm{C}$ is derived from animals imported to the US for immediate slaughter, whereas that under label B is not, with 'immediate' defined as within two weeks of being imported into the US.

As is clear, the information disseminated via COOL concerned three stages in the production of meat: place of birth of the animal, where it had been raised, and where it was slaughtered. The COOL statute permitted the use of a common label if livestock with different labels were 'commingled' in feedlots and/or slaughterhouses on a single production day. For example, label B could be used if there was commingling between livestock with labels $\mathrm{A}$ and $\mathrm{B}$. As a result of rules pertaining to commingling, meat sold under label B could actually have come from an animal with $100 \%$ US origin. This possibility was seen by the Panel to be relevant for determining whether US-COOL conveyed accurate and clear information to consumers.

2 Horn and Weiler (2007) provide an excellent survey and critical analysis of the issues discussed.

3 The only area of the TBT Agreement that case law has not yet dealt with is conformity assessment.

4 Howse and Levy (2012) offer a masterful critical discussion of the three Panel reports.

5 COOL stands for 'country of origin labelling'. 
Mexico and Canada successfully challenged the COOL measure, arguing that it was both unnecessary, as well as discriminatory; a claim challenging the legitimacy of the objective pursued was also submitted by the complainants. The Panel found that the COOL measure violated Article 2.1 of the TBT because it afforded 'imported livestock treatment less favourable than that accorded to like domestic livestock' and also Article 2.2 of the same Agreement because it did not 'fulfil the objective of providing consumer information on origin with respect to meat products'. Thus, while the Panel did find that providing consumers more information was a legitimate objective for introducing technical regulations to that effect, its judgement was that the US policy resulted in 'de facto' discrimination by changing the 'conditions of competition' against imports while also failing to meet its intended objective since the 'COOL measure falls short of providing consumers with information on the country of origin of meat products in an accurate and clear manner'.

In Section 2, we explain briefly the legal discipline imposed on WTO Members by the TBT Agreement, as well as the findings of the AB. Section 3 includes our critical evaluation of the $\mathrm{AB}$ report. In this section, we adopt the methodology of the $\mathrm{AB}$ without questioning its usefulness and/or rationality, and explain why, in our view, the $\mathrm{AB}$ should not have decided the case as it did even within the four corners of its preferred methodology. In Section 4, we move to a more normative discussion, and present our own preferred methodology. Here, we argue that the $A B$ should not have imported the GATT method of analysis 'lock, stock, and barrel' into the TBT Agreement, but should have first inquired about the underlying objectives of the TBT Agreement and only then applied its legal test to the facts of the case. Section 5 recaps our main conclusions.

We next discuss the findings of the $\mathrm{AB}$ that were called into play because different aspects of the Panels' report invited appeals from the US and Canada.

\section{The Findings of the $A B$}

The $\mathrm{AB}$ had to address essentially three claims:

(a) whether the US measure pursued a legitimate objective;

(b) if yes, whether the US measure was necessary to achieve that objective; and

(c) whether the US measure was non-discriminatory in nature.

None of the parties appealed the Panel decision to subject the COOL measure under the coverage of the TBT Agreement. Recall that, a WTO Member must, when enacting a measure coming under the purview of the TBT Agreement ensure that it is necessary to achieve the envisaged objective, that it is applied in a nondiscriminatory manner, and that it is, in principle, based on an international standard, assuming a relevant international standard exists. 
Three classes of measures come under the purview of the TBT Agreement: technical regulations, standards, and conformity assessment procedures. A technical regulation is defined in the Annex to the TBT Agreement as follows:

Document which lays down product characteristics or their related processes and production methods, including the applicable administrative provisions, with which compliance is mandatory. It may also include or deal exclusively with terminology, symbols, packaging, marking or labelling requirements as they apply to a product, process or production method.

The same Annex contains a definition of the term 'standard':

Document approved by a recognized body, that provides, for common and repeated use, rules, guidelines or characteristics for products or related processes and production methods, with which compliance is not mandatory. It may also include or deal exclusively with terminology, symbols, packaging, marking or labelling requirements as they apply to a product, process or production method. ${ }^{6}$

In this case, there was no challenge against the Panel decision to classify the labelling requirements provided for in the COOL measure as a 'technical regulation'.

To gain an informed perspective on the findings of the $\mathrm{AB}$ (analyzed in detail below), we briefly discuss the nature of the North American market for cattle and hogs. Our discussion is based on the facts presented in Jurenas and Greene (2013). First, in this market, the US exports much less than it imports from its neighbours: in 2012, US exports of cattle and hogs to Canada and Mexico were only $\$ 48$ million whereas its imports were nearly $\$ 2.1$ billion (over 40 times). Second, almost all live cattle imports into the US come from its two neighbours: live hog imports come primarily from Canada while feeder cattle (i.e. cattle placed on feed lots or pasture prior to slaughter) come mostly from Mexico. Third, and perhaps most importantly, the market share of domestic meat suppliers is large: since 2000, cattle imports have accounted for only about $6 \%$ of total cattle slaughtered in the US with the figure for hogs being roughly the same. As we will see below, the overwhelming dominance of local meat suppliers was crucial for the argument of de facto discrimination, carrying the day in favour of the complainants.

\subsection{Was the US pursuing a legitimate objective through US-COOL?}

Article 2.2 TBT reads:

Members shall ensure that technical regulations are not prepared, adopted or applied with a view to or with the effect of creating unnecessary obstacles to

6 In other words, the definitions of the two instruments are similar except that compliance is necessary only with technical regulations for market access to be guaranteed. The obligations regarding conformity assessment were not an issue in this dispute. An analysis of the legal obligation associated with conformity assessment is beyond the scope of this paper. 
international trade. For this purpose, technical regulations shall not be more trade-restrictive than necessary to fulfil a legitimate objective, taking account of the risks non-fulfilment would create. Such legitimate objectives are, inter alia: national security requirements; the prevention of deceptive practices; protection of human health or safety, animal or plant life or health, or the environment. In assessing such risks, relevant elements of consideration are, inter alia: available scientific and technical information related processing technology or intended end-uses of products. (Italics in the original)

The objective sought through the COOL measure was discussed in $\$ 6.113$ of the Panel report on US-COOL, where the Panel noted that:

the objective as identified by the United States was 'to provide consumer information on origin'. The Panel was not presented with the argument from the United States that the reduction of compliance costs for market participants also formed part of the objective pursued by the United States through the COOL measure. As Mexico points out, the United States submitted that reducing compliance costs was one of the factors that it considered in implementing the COOL measure to achieve the objective of providing consumer information on origin. Reducing compliance costs therefore cannot form part of the objective itself. (Emphasis in the original)

Typically, Panels have tended to adopt deferential attitudes (towards the regulating WTO Member) when it comes to reviewing the legitimacy of an objective pursued. In US-COOL, the Panel specified that the regulating state must define its objectives and pursue them in a coherent (e.g., not self-contradictory) manner, while underscoring that WTO Members remain exclusively responsible for defining the objectives pursued (\$\$ $7.611 \mathrm{ff}$.). On appeal, in $\$ 372$ the $\mathrm{AB}$ confirmed this approach and added:

With respect to the determination of the 'legitimacy' of the objective, we note first that a panel's finding that the objective is among those listed in Article 2.2 will end the inquiry into its legitimacy. If, however, the objective does not fall among those specifically listed, a panel must make a determination of legitimacy. It may be guided by considerations that we have set out above, including whether the identified objective is reflected in other provisions of the covered agreements.

In $\$ 410$, the $\mathrm{AB}$ added:

Canada asserts that the fact that the COOL measure applies to some products that do not have USDA grade labelling, and does not apply to others that do, calls into question whether the measure really aims to prevent consumer confusion. Even if this were true, however, Canada has not explained why this would necessarily also vitiate the Panel's finding that the objective of the COOL measure is to provide consumers with information on origin.

The AB thus found that Panels do not violate their duty to perform an objective assessment when trying to identify the objectives sought through a national legislation, and that WTO Members aiming at challenging inconsistent, in their 
view, objectives, carry the associated burden of proof. Canada did not manage to persuade neither the Panel nor the AB that the US had violated Article 2.2 TBT in this respect.

Country of origin labels can provide useful information to consumers. Indeed, country of origin labels are used widely across the world and are sometimes even used by private retailers to signal the source of a particular product - for example, lamb from New Zealand. Presumably, consumers value such information because national origin can sometimes signal quality. But this is not the only reason why consumers might value information regarding national origin of products. For example, the 'local food' movement is motivated by social concerns having to do with the environmental externalities created by food that travels long distances. This is not to say, of course, that meat sold under label A under US-COOL would necessarily fit the criterion of being locally sourced from an environmental perspective: imported meat from cattle slaughtered in Mexico could be more 'local' for consumers in Texas than that sourced from a slaughterhouse in a mid-western US state. Nevertheless, consumers are free to make such choices only if national origin is indicated on the meat product, which was the main objective of the US-COOL statute.

From an economics perspective, the fact that the market had not resorted to widespread use of labels distinguishing US meat from Canadian and Mexican meat prior to COOL raises the legitimate question of whether consumers really wanted the information that is provided by COOL. While this is a fair concern, and one that was even acknowledged by the USDA, it does not, in of itself, imply that the stated intent behind the US regulation (i.e. of providing consumers with more information) was not legitimate and/or outright protectionist, as was charged by the complainants. A long and well-established literature in economics highlights how the presence of incomplete and/or asymmetric information can affect market outcomes in adverse ways and how the market for information itself is subject to various types of failures. Furthermore, individual consumers valuing such information may have neither the incentive nor the means to ensure that the market indeed provides it, particularly if the benefit to each individual consumer of such information is relatively small even though the collective benefit to all of them is large.

It is also worth clarifying that country of origin labelling requirements with respect to animal products had already been introduced in the US via the 2002 Farm Bill that obligated retailers to provide such information for a wide range of commodities including beef, pork, lamb, and fish. However, this 2002 Bill was silent on how products derived from animals originating outside the US were to be labelled; it simply restricted the US-origin label to those products that were derived totally from within (i.e. were born, raised, and slaughtered in the US as would be the case for those carrying label A under COOL). Thus, US COOL expanded this original 2002 scheme by specifying how to label meat products that were derived, at least in part, from outside the US. 


\subsection{Was US-COOL Non-Discriminatory?}

Under Article 2.1 TBT:

Members shall ensure that in respect of technical regulations, products imported from the territory of any Member shall be accorded treatment no less favourable than that accorded to like products of national origin and to like products originating in any other country.

The US never claimed that beef of foreign origin was unlike product to US beef. The only legal issue under Article 2.1 TBT was whether the US, through the challenged measure, was affording less favourable treatment to imported beef relative to domestic like goods. The complainants maintained that this had effectively been the case, since the requirements for multiple-origin beef were more onerous than those imposed on single-origin beef, and that, consequently, traders would favour US beef. The Panel found in $\$ \mathbb{\$ 7 . 3 4 9 -}$ 7.350 that:

Turning to the scenarios involving either exclusively domestic or exclusively imported livestock, it seems logical that the scenario of processing exclusively domestic livestock and meat is in general less costly and more viable than processing exclusively imported livestock. Livestock imports have been and remain small compared to overall US livestock production and demand, and US livestock demand cannot be fulfilled with exclusively foreign livestock. And even if it could be, in light of the evidence before us, it appears that this scenario would in all likelihood involve more than one foreign origin, and thus in general more segregation and higher compliance costs than processing exclusively domestic livestock, which by definition has one single origin. Also, in general, US livestock is often geographically closer to most if not all US domestic markets, so processing exclusively imported livestock and meat remains a relatively less competitive option.

As a result, overall, the least costly way of complying with the COOL measure is to rely on exclusively domestic livestock. Thus, in general, business scenarios involving imported livestock, including the scenario involving exclusively imported products, are overall more costly than the exclusively Label A approach.

On appeal, the $\mathrm{AB}$ first noted:

In assessing even-handedness, a panel must 'carefully scrutinize the particular circumstances of the case, that is, the design, architecture, revealing structure, operation, and application of the technical regulation at issue ( $\$ 271)$.

Following a long discussion ( $\$ \$ 287 \mathrm{ff}$.), the $\mathrm{AB}$ applied this test to the specifics of the case underscoring that the existence of detrimental impact on imported goods does not ipso facto amount to less favourable treatment; it does only if it cannot be justified as the outcome of pursuing a legitimate objective. In this case, the AB sided with the Panel when finding that the COOL measure could not be justified on these grounds; the detrimental impact was not stemming exclusively from the pursuance 
of a legitimate objective but also from the arbitrary and unjustifiable regulatory distinctions that the COOL measure had introduced $(\$ 349)$ :

In sum, our examination of the COOL measure under Article 2.1 reveals that its recordkeeping and verification requirements impose a disproportionate burden on upstream producers and processors, because the level of information conveyed to consumers through the mandatory labelling requirements is far less detailed and accurate than the information required to be tracked and transmitted by these producers and processors. It is these same recordkeeping and verification requirements that 'necessitate' segregation, meaning that their associated compliance costs are higher for entities that process livestock of different origins. Given that the least costly way of complying with these requirements is to rely exclusively on domestic livestock, the COOL measure creates an incentive for US producers to use exclusively domestic livestock and thus has a detrimental impact on the competitive opportunities of imported livestock. Furthermore, the recordkeeping and verification requirements imposed on upstream producers and processors cannot be explained by the need to convey to consumers information regarding the countries where livestock were born, raised, and slaughtered, because the detailed information required to be tracked and transmitted by those producers is not necessarily conveyed to consumers through the labels prescribed under the COOL measure. This is either because the prescribed labels do not expressly identify specific production steps and, in particular for Labels B and C, contain confusing or inaccurate origin information, or because the meat or meat products are exempt from the labelling requirements altogether. Therefore, the detrimental impact caused by the same recordkeeping and verification requirements under the COOL measure can also not be explained by the need to provide origin information to consumers. Based on these findings, we consider that the regulatory distinctions imposed by the COOL measure amount to arbitrary and unjustifiable discrimination against imported livestock, such that they cannot be said to be applied in an even-handed manner. Accordingly, we find that the detrimental impact on imported livestock does not stem exclusively from a legitimate regulatory distinction but, instead, reflects discrimination in violation of Article 2.1 of the TBT Agreement. (Italics in the original).

\subsection{Was US-COOL Necessary?}

The Panel had found that the US measure was more restrictive than necessary to achieve its legitimate objective, but the $\mathrm{AB}$ reversed the Panel's finding in this respect. It did not complete the analysis, though, since in its view it lacked the necessary factual information to this effect. As a result, the $\mathrm{AB}$ did not make a finding regarding the necessary character (or not) of the COOL measure.

\subsection{The AB findings in a nutshell}

The $\mathrm{AB}$ found that the measure was discriminatory; it did not make any finding regarding the issue of whether the COOL measure was necessary to achieve its stated objective; and, finally, it did not reverse the Panel's findings that the measure 
was indeed pursuing a legitimate objective, namely consumer information regarding the origin of traded goods.

\section{A critical evaluation of the $A B$ report: positive analysis}

\subsection{Legitimate objective}

On the specific issue of legitimacy of the objective, there is not much to add to the discussion by the Panel and the AB. Indeed, we share the view that WTO Members should be allowed to unilaterally define the legitimate objective they aim at pursuing, and that WTO adjudicating bodies should adopt a deferential standard of review when dealing with claims regarding the legitimacy of the objective pursued. WTO adjudicating bodies, it seems, avoid tinkering too much with national definitions in this context. This approach is consonant with the negative integration character of the TBT Agreement (and the GATT, to which the TBT Agreement is an Annex): policies will be defined unilaterally and (negative) external effects eventually stemming from policies should be internalized through the obligations to avoid unnecessary and/or discriminatory obstacles to trade.

The indicative list of legitimate objectives provided for in Article 2.2 TBT serves, in our view, two objectives:

(a) To underscore the wide discretion that WTO Members enjoy when it comes to deciding which policies to pursue: they can pursue policies that have not been included in the list.

(b) To avoid Type II errors (false negatives) by the judges who must accept as legitimate an objective featured in the indicative list.

The question arises to what extent they should also accept as legitimate any objective not mentioned in the list that has been invoked by a WTO Member, or to what extent they retain some discretion to this effect. This question, nevertheless, was not raised in this dispute. ${ }^{7}$

\subsection{Less favourable treatment}

Recall that in $\$ 349$ of the report on US-COOL cited above, the $\mathrm{AB}$ had found that the treatment afforded to imported beef was less favourable than that reserved for domestic beef. The $\mathrm{AB}$ found that:

(a) The COOL measure was the reason for segregation which led to privileging the trade of US-origin beef; and that

(b) the disparate impact on mixed-origin beef could not be justified by the need to inform consumers, for the following reasons:

7 We believe nevertheless, that the $\mathrm{AB}$ got it right in US-Clove Cigarettes, where it stated that WTO Members cannot be inconsistent when pursuing a regulatory objective. A consistency-requirement, if properly implemented, will help adjudicators distinguish wheat from chaff in this respect. 
- more information was requested from producers than was being disseminated to consumers;

- the information transmitted to consumers was inaccurate, because of the possibility of 'commingling': sometimes the three individual production stages corresponding to where traded livestock was born, raised, and slaughtered were not accurately reflected in the label, since traders could 'commingle' two different stages into one; and

- because some 'pa and ma' stores had been exonerated from the obligation to observe the COOL measure. ${ }^{8}$

The existence of detrimental impact on multi-origin livestock was not in the eyes of the $\mathrm{AB}$, in and of itself, enough to lead to the conclusion that the US, through the COOL measure, was affording imported livestock less favourable treatment than it was affording to domestic livestock: it might have been a necessary, but not a sufficient condition. The sufficient condition would be fulfilled if the foreign origin of the good had been the reason for the detrimental impact suffered by it. This had been the case indeed, since the $\mathrm{AB}$ was not persuaded that the dissemination of information to consumers could have motivated the COOL measure for the reasons mentioned above (e.g. more information requested than disseminated, inaccurate information disseminated at times, exoneration of 'pa and ma' stores).

Two questions arise: first, what is the standard of review that the $\mathrm{AB}$ employed to reach these conclusions, and, second, on what evidentiary basis did the $\mathrm{AB}$ make its determination? We take each one in turn.

\subsubsection{The standard of review applied}

In $\mathbb{S} 127-129$ of its report, the $\mathrm{AB}$ explained in detail its standard of review:

(a) WTO adjudicating bodies must establish a cause and effect relationship between the challenged measure and the observed effects that denote less favourable treatment;

(b) To do that, a 'but-for' test is appropriate, that is, adjudicating bodies should ask whether private operators would have adopted a particular attitude but for the government's intervention;

(c) There is no need to show government compulsion; it suffices that the governments provide private operators with an incentive to behave in a particular way.

8 US-COOL had many built-in exemptions. It applied only to muscle cuts and exempted ground beef and pork sold at the retail level. US-COOL also exempted retailers who sold less than $\$ 230,000$ worth of fruits and vegetables per year (so that small stores and butcher shops were exempt) as well as food service establishments such as restaurants and cafeterias. Furthermore, all processed food items (such as cooked, cured, and smoked meats) also did not need to carry country of origin labels. Taken together, these exemptions implied that less than half the meat sold in the US was covered by COOL requirements at the retail level (see Jurenas and Greene, 2013). 
Making repeated references to its report on Korea-Various Measures on Beef, the $\mathrm{AB}$ explained that segregation (e.g. privileging single-origin US beef) was not compelled, but the result of the incentives that traders now faced because of the enactment of the labelling measures by the US government.

In $\$ 316$ of its report, the $\mathrm{AB}$ went so far as to state that the Panel did not need to show trade effects to reach its conclusion, a statement which is in compliance with past case law (the GATT Panel on US-Superfund providing the authority for this standard of review). Yet, it is trade effects, as we show in what immediately follows, that formed the Panel's view on this issue. To be fair, it is unclear whether the $\mathrm{AB}$ understands 'price effects' to be 'trade effects', or whether the latter term is confined to a narrower ambit, namely the consequence of price effects, e.g. the volume of beef sold as Label A, B etc. If this latter view were correct, then why did not the $\mathrm{AB}$ simply use the term 'volume'? Be it as it may, and in effort to avoid misunderstandings, we reproduce the basis of the AB's findings in what follows.

\subsubsection{The evidentiary basis for the findings}

As the $\mathrm{AB}$ did not disturb the Panel's findings in this respect, it is probably worth referring to the relevant excerpts of the Panel report. In $\$ 7.356$, the Panel refers to discounts provided by slaughterhouses for US beef only:

In fact, there is direct evidence of major slaughterhouses applying a considerable COOL discount of USD 40-60 per head for imported livestock. This proves that major processors are passing on at least some of the additional costs of the COOL measure upstream to suppliers of imported livestock. We have no evidence of a similar discount being applied to suppliers of domestic livestock, nor has the United States responded to the evidence submitted by Canada and Mexico in this respect.

There is no evidence that the slaughterhouses offered discounts because of the COOL labelling measures. Canada submitted a few affidavits to this effect, but this is all it submitted. ${ }^{9}$ All we know is that discounted prices were offered to some but not for other beef, and one could imagine various reasons why this could have occurred. Based on this fact alone, we cannot even say for sure whether the government intervention was (a significant?) contributing factor.

In $\mathbb{\$}$ 77.376-7.381, the Panel provides additional information evidencing reduced market opportunities for imported livestock (labels B, C, and D). The Panel refers to fewer processing plants accepting imported livestock, reduced opening hours etc., and every time it affirms that this is the result of enacting the COOL measure:

Moreover, as a result of the COOL measure, fewer US processing plants are accepting imported livestock than before. The complainants have submitted maps

9 We return to this question infra. 
and lists of US processing facilities showing how US processing plants have become less accessible for imported cattle and hog under the COOL measure. Although the United States contests the specific figures submitted by the complainants in this regard, it does not call into question the complainants' case on the overall reduction in the number of plants processing imported livestock as a result of the COOL measure.

We also have evidence before us showing that, as a result of the reduction of available processing plants, certain suppliers had to transport imported livestock longer distances than before the COOL measure. Further, several plants that continue to process imported livestock do so at specific, limited times, namely only on specific days of the week (typically at most one or two days per week), or only after specific hours of the day. Processing imported livestock only at specific times as a result of the COOL measure has created logistical problems and additional costs for certain imported livestock suppliers. Due to the congestion resulting from limited specific-time deliveries, certain imported livestock suppliers find it more difficult to obtain trucks for their deliveries or to use their trucks in an efficient way. Congestion has also increased waiting time for imported livestock crossing the border, and thus created transportation delays for certain suppliers of imported livestock. In turn, these have increased the transportation costs of certain suppliers of imported livestock, and have had a negative impact on the welfare and quality of imported livestock as a result of long waiting times in extreme temperatures and shrinkage, sometimes leading even to increased mortality. Also, transportation of imported livestock has become less efficient in that certain suppliers can make fewer deliveries due to longer distance transport and less turn-around time. Further, certain slaughterhouses accepting imported livestock only on Monday has resulted in increased costs for veterinary checks of imported livestock on Sunday.

Contractual terms for suppliers of imported livestock have also changed as a result of the COOL measure. We have evidence that several major processors introduced a COOL opt-out clause allowing them to unilaterally terminate or amend their contracts with suppliers of imported livestock. In certain other situations, supply contracts for imported livestock have been cancelled or terminated, or simply not renewed. Sometimes, the contractual relationship has survived the COOL measure, although at terms less favourable for imported livestock suppliers. For instance, in certain cases, former long-term contracts have been replaced with spot contracts at lower purchase prices. In at least one case, a former automatically renewed, 'evergreen' contract was replaced with a contract involving less favourable terms. Further, we have evidence of 14 days' advance notice being required for supplies of Mexican cattle at various US processing facilities.

Certain suppliers of imported livestock have also suffered significant financial disadvantages resulting from the COOL measure. Several suppliers reported that the price difference between imported and domestic livestock has become larger to the detriment of domestic livestock, and that discounts for imported livestock appeared or existing ones increased as a result of the COOL measure. Further, in several cases, financial institutions are reported to have refused to provide credits 
and loans to Canadian livestock producers due to the risks resulting from the COOL measure.

Finally, we have evidence before us - undisputed by the United States - that imported cattle have been excluded from premium beef programmes, such as the Certified Angus Beef programme and other programmes, as a result of the COOL measure. In general, these premium programmes are particularly profitable for operators in the supply chain, including livestock suppliers.

In light of the above considerations, we preliminarily conclude that the COOL measure reduces the competitive opportunities of imported livestock relative to domestic livestock. Before making a definitive finding on this matter, though, we need to address the counterarguments advanced by the United States in this regard.

The natural question to ask is how did the Panel attribute the effects discussed (reduced market opportunities, discounts etc.) to the enactment of the COOL measure? In other words, what is the intellectual process that allowed the Panel to establish a cause and effect relationship between the passage of the COOL measure and the less favourable treatment afforded to imported livestock? Econometric studies can help determine whether there existed a statistically significant relationship between the COOL measure and the competitive opportunities facing imported livestock relative to US livestock. Indeed, to reach the conclusion that a relationship between the challenged measure and disparate effects indeed existed, the Panel did base its decisions on econometric studies. The Panel noted, however, that it also took into account other evidence before it that was provided through affidavits etc. The Panel did not explain how each of the factors (econometric studies vis-à-vis affidavits) weighed in its evaluation, but did state that it did not base itself entirely on the econometric studies submitted. Recall, that what is of interest to us here is the intellectual process that allowed the Panel to establish that the COOL measure was associated with detrimental effects on imported livestock. The AB took the view that the Panel had not erred in its evaluation of the record before it. In $\mathbb{\$} \$ 325-326$ of its report, the AB held that:

In addition, as explained above, the Panel evaluated the Sumner Econometric Study as part of its examination of the actual trade effects of the COOL measure. The Panel made explicit that its finding of less favourable treatment was not dependent on its examination of the actual trade effects of the COOL measure and the evidence relating to such effects. Nor was the Panel required under Article 2.1 to confirm its legal conclusions based on the actual trade effects of the measure in the US market. We therefore consider that, even if the Panel were to have erred in its appreciation of the Sumner Econometric Study, such an error would not have materially affected its ultimate legal conclusion under Article 2.1 of the TBT Agreement.

We therefore find that the United States has not demonstrated that the Panel acted inconsistently with Article 11 of the DSU in its assessment of the evidence relating to the price differential between domestic and imported livestock. 
Footnote 622 exacerbates this finding while underlying what else the Panel observed that persuaded it that less favourable treatment had indeed been afforded to imported livestock:

That is, the Panel found that: (i) fewer processing plants are accepting imported livestock, and those that do, do so at specific limited times; (ii) contractual terms for suppliers of imported livestock have changed as a result of the COOL measure; (iii) certain suppliers of imported livestock have suffered significant financial disadvantages resulting from the COOL measure, including an increased price differential between imported and domestic livestock and the refusal of financial institutions to provide credits and loans; and (iv) imported cattle have been excluded from profitable premium beef programmes.

(a) The econometric studies: The $\mathrm{AB}$, siding with the Panel on this score, went on to suggest that the more onerous reporting requirements for $\mathrm{B}$ and $\mathrm{C}$ categories (multi-origin beef) pushed traders to segregate and favour US beef. What did the submitted econometric evidence suggest to this effect? Two studies were submitted to the Panel by Canada, referred to as the 'Informa study' and the 'Sumner report' . The focus of each study was different: the Informa study focused on the implementation costs of supply chains and the Sumner report on the willingness of operators along the supply chain to pay for mixed-origin beef. The former, because of its subject-matter, did not squarely address the issue of attribution (of detrimental effects to the COOL measure) that we care most about. Moreover, in \$7.499, the Panel explicitly stated that it cannot assess if it contains reliable information due to two factors: it was silent on its methodology as well as on the sample on which its findings were based. We are thus, left with the Sumner report.

In order to assess the willingness of traders to purchase mixed-origin beef or hog, the Sumner report compared the situation before and after the enactment of the COOL measure. This report concluded that, relative to goods originating from a single country, mixed-origin goods would become costlier due to COOL but that not all of the additional costs would be passed on to consumers (especially in the hog market). ${ }^{10}$ Consequently, the Sumner report concluded that the enactment of the COOL measure would lead to increased purchases of US hogs at the expense of those that had a mixed origin.

We should note that the Panel in $\$ 7.506$ of its report had accepted that for various reasons it could not rely on the figures included in the Sumner report. This conclusion notwithstanding though, the Panel took the view that the two studies pointed to segregation costs which led traders towards privileging US-origin livestock.

10 Indeed, anytime the costs of a product increase (either due to market conditions or due to a regulation such as US-COOL), the extent of pass through to consumers is determined jointly by the elasticities of supply and demand. Only in a situation of perfectly inelastic demand are cost increases passed on entirely to consumers. 
Let us assume that segregation did occur, that is, that segregation was the rational economic response of various market agents to the enactment of the COOL measure. Why would US beef be necessarily favoured as a result, and not Mexican, or Canadian, or any beef produced in a single country? Even if we take the most favourable view of the studies, they at best show that the measure provided an incentive for traders to move from mixed-origin to US-origin livestock in a world with no other options. However, other options are available and that is why Label D exists. From what we observe in the record, none of the studies asked whether segregation would (could) lead to increased purchases of US- over Mexican- or Canadian-origin beef/hog. Privileging US-origin beef is, at best, one plausible scenario. There exists other (equally or, probably, even more) plausible scenarios though: would, for example, traders still prefer US beef if Mexican (or Canadian) beef was significantly cheaper? We have nothing in the record that suggests that segregation would lead to preference for US beef over Mexican or Canadian beef, other than a Panel opinion that traders would prefer US beef because of the geographic proximity. ${ }^{11}$ If geographic proximity was the decisive criterion for purchasing decisions though, there would of course be no trade at all in the majority of products. Moreover, why would geographic proximity lead traders to prefer US livestock? Traders in the Southern states of the US are certainly closer to Mexican livestock, and traders in the Northern states to Canada. In the AB's view then a substantial percentage of US traders would prefer Canadian and Mexican and not US livestock.

From a purely legal perspective, less favourable treatment invites a comparison between a domestic and an imported good. By contrast, the comparison drawn here is between a domestic and a multi-origin (including domestic-origin) good. We have no idea what the national (e.g. US, Canadian, or Mexican) value-added of each country is when dealing with multi-origin livestock. What if, for example, the US share of valued-added in multi-origin beef is consistently $90 \%$ ? Would the Panel still find that less favourable treatment to imported livestock had been afforded through the COOL measure?

In our view, this is very shaky evidence to conclude that less favourable treatment has indeed been afforded. The Panel should, at the very least, have asked for additional information. As things stand, it had no basis to conclude that the US was in violation of its obligations and the $\mathrm{AB}$ moved too fast to condone this approach. (b) Other evidence: The Panel, as already mentioned above, had before it affidavits submitted by Canada regarding discounts offered for US-origin beef only. Based on similar documents as well (e.g. besides the 'persuasive' power of the

11 Hence, we are not here in a 'raising the rival's cost' scenario. The AB does not believe that market analysis is warranted since it has always construed provisions regulating non-discrimination as protecting competitive conditions; to this effect, violations can occur (in the eyes of the $\mathrm{AB}$ ) even if no data on trade effects have been provided. Moreover, why would geographic proximity lead traders to prefer US livestock? 
econometric studies submitted), it concluded that the US was in violation of its obligations. These documents, however, contained absolutely no information on the question of attribution; they simply showed that price discounts were being offered. This evidence could thus at best complement evidence on attribution; it could not be regarded as substitute for attribution analysis. This evidence also suffers from the same vice as the econometric studies: the comparator is inappropriate since we have no information on whether similar discounts were also offered on Canadian, Mexican, or any other single-origin beef.

(c) Discrepancy in the amount of information requested: Both the Panel as well as the $\mathrm{AB}$ report concluded that there was discrepancy regarding the amount of information requested from traders, and the information eventually disclosed to the public. This cannot be an issue though when the consistency of the US measure with the obligation to not discriminate is being discussed, since more information, on the face of it, is requested from both domestic as well as imported beef. If at all, this could be an issue when the necessity of the measure is being evaluated. As we have already seen though, the $\mathrm{AB}$ reversed the Panel's findings with respect to the violation of the necessity-requirement, and did not complete the analysis.

How might the US eliminate the discrepancy between the amounts of information requested from producers to that supplied to consumers? There are essentially two ways. One, the US could scrap the COOL measure altogether thereby eliminating the need for both the collection and dissemination of information regarding the source of origin of meat products. Second, the US could actually make the labelling process more elaborate rather than less. For example, the US could require that each piece of meat being sold in the US should indicate exactly where each of three steps in the processing of livestock (i.e. born, raise, and slaughtered) took place. Under this alternative scheme, restricting attention to only the three countries involved in the dispute, the US would need to create NINE different labels since each of the three steps could potentially be carried out in any of the three countries. Perhaps this more extensive labelling practise would minimize the informational discrepancy dimension that seems to be crucial to the AB's reasoning. But what about the additional record keeping and other costs that would result from its implementation? Such costs would almost surely be higher under this more elaborate labelling scheme relative to US-COOL. Consequently, it would appear that this scheme would be even more susceptible to the de facto discrimination against imports charge that seems to have carried the day against US-COOL.

\section{A critical evaluation of the $A B$ report: normative analysis}

\subsection{The $A B$ approach}

The $\mathrm{AB}$ found that the measure was discriminatory, although it made no finding regarding its necessity. The $\mathrm{AB}$ thus, understood the two obligations to be distinct, 
in that, the consistency of a measure coming under the purview of the TBT Agreement can be examined under say Article 2.1 TBT irrespective of its evaluation under Article 2.2 TBT. We believe that the approach followed is correct only for a very narrow set of circumstances; namely, when it comes to cases of alleged de jure discrimination. When for example a national labelling scheme (like the COOL measure) adopts one set of requirements that domestic goods must in principle comply with, and another, more onerous set of requirements that imported goods must observe for market access to be guaranteed, then yes, one can review the consistency of similar measures under Article 2.1 TBT while avoiding to do so under Article 2.2 TBT.

In cases of alleged de facto discrimination, we need additional information to evaluate the functioning of the measure and this brings us squarely into the realm of Article 2.2 TBT. Recall it was the AB that suggested that a finding of less favourable treatment does not solely depend on the existence of disparate effects; the challenged measure, and no public order justification (in our case, consumer information), must be causing the observed (adverse) trade effect. Information thus, about the objectives sought and the means employed to reach the objectives sought, is necessary for deciding whether a measure de facto discriminates if we are to respect the standard of review as established by the $A B$, and which seems reasonable to us as well.

There should be no doubt that we are dealing with a case of alleged de facto discrimination: domestic as well as foreign beef must observe the same labelling conditions; it is the consequences (as opposed to conditions) of the labelling scheme that, if at all, lead to less favourable treatment.

\subsection{Our approach}

In our view, the claims made by Canada and Mexico against the COOL measure should have been addressed in a sequential manner:

(a) Does the COOL measure pursue a legitimate objective?

- If no, complainants prevail.

- If yes, then we move to the next question.

(b) Is the COOL measure necessary to achieve the legitimate objective pursued?

- If no, complainants prevail.

- If yes, we move to the next question.

(c) Has the COOL measure been applied in a non-discriminatory manner?

- If no, complainants prevail.

- If yes, defendant prevails. ${ }^{12}$ 


\subsubsection{The mechanics}

Since we are not dealing with a case of de jure discrimination here (e.g. differential regulatory requirements apply to products depending on their origin), the Panel and the $\mathrm{AB}$ should have first asked whether the challenged measure pursued a legitimate objective, and also respected the necessity-requirement embedded in Article 2.2 TBT in this context, the Panel could have quantified the 'external' costs of the challenged measure, that is, the costs on international trade, and could have asked the question whether the objective sought (consumer information) which it could not put into question, could have been achieved through another means that were less burdensome on international transactions; if the response was positive, following allocation of the burden of proof à la US-Gambling, the US should lose the argument, and in the opposite case it should have prevailed. Winning under Article 2.2 TBT though, should not be equated to winning full stop: assuming a claim to this effect, the Panel and the AB should have examined whether the necessary labelling requirements had been applied in a non-discriminatory manner to domestic and imported livestock alike.

This entails one important consequence: in our framework of analysis, the obligation to avoid discrimination (embedded in Article 2.1 TBT) is an obligation regarding the application of the challenged measure. The substantive consistency of the measure with the multilateral rules will take place within the four corners of Article 2.2 TBT: the question should be whether the US had applied the (otherwise necessary) labelling requirements in a non-discriminatory manner across livestock of different origins. If the labelling requirements were deemed necessary to achieve the stated objective (consumer information), the Panel and the AB should have asked whether the same labelling requirements were being applied to domestic and imported like goods. ${ }^{13}$ Everything else should be an examination under Article 2.2 TBT.

\subsubsection{The rationale for our sequential approach}

The heart of the problem we perceive in the analysis by the AB is the 'lock, stock, and barrel' export of GATT solutions (inspired by case law under Article III) to the TBT Agreement; indeed, the AB did nothing other than apply its test of consistency with Article III.4 GATT (as developed in various cases) into the realm of the TBT. The GATT however was drafted without thinking too much about disciplining regulatory barriers. ${ }^{14}$ According to Baldwin's (1970) classic account, this was the right thing to do at the time since trade barriers (e.g., high tariffs, quotas) obscured the 'bite' of regulatory barriers (e.g., domestic instruments). Under the circumstances, it was only sensible for the framers to focus on disciplining trade rather

13 Mavroidis (2013) contains a more expansive discussion of this issue and point of view.

14 Irwin et al. (2008) reach this conclusion after examining a very substantial percentage of the negotiating record. 
than domestic instruments. Following the Kennedy round, every round (including the on-going Doha round) has mainly focused on disciplining regulatory barriers: once again, this is only sensible since import and export quotas are illegal, and tariffs have been gradually reduced to an all-time low. ${ }^{15}$ The TBT Agreement is an integral part of this discussion and focuses on disciplining some regulatory barriers.

The TBT Agreement does not put into question the right of governments to be unhappy with market outcomes. It does not even proscribe which market outcomes governments can be unhappy with: this is the natural consequence of its negative integration character. The TBT Agreement conditions the exercise of the right of WTO Members to intervene and alter the market outcome. Consequently, the domain of the TBT Agreement is policy and not market likeness.

\subsection{What can the US do as things stand?}

As things stand, it seems there is no way out for the US other than to scrap the COOL measure altogether since the alternative of introducing more elaborate labelling schemes would be even more susceptible to the charge of de facto discrimination that seems to have carried the day in favour of the complainants. The basis of the decision is that the challenged regime leads to segregation of beef and ultimately to privileging US-origin beef by altering the conditions of market competition in its favour. There is thus, in the AB's understanding, an inherent vice in this measure which cannot be cured as long as the US insists on adopting a technical regulation. Price discounts etc. are the almost natural consequence, in the AB's reasoning, of the enactment of the COOL measure.

Note that the logic behind this charge is that since a large part of the meat is actually locally sourced (i.e. from within the US), all else equal, there is an incentive for meat processing units to shift almost entirely to US meat in order to avoid the costs of tracking and segregating meat from multiple sources. To avoid being foreclosed on, Canadian and Mexican suppliers would have to accept a lower price to make it worthwhile for downstream producers to source from all three countries as opposed to only the US. But what if the market share of foreign meat suppliers was almost $50 \%$ but still below that of the US? Would there be de facto discrimination even then? If yes, does it mean that labelling requirements such as US-COOL can only be used when the market share of imports is exactly equal to that of domestic suppliers?

This is not all. The AB's decision raises some other fundamental questions: Are we in the presence of a case where a legitimate objective (i.e. consumer information about the origin of birthplace, place of growth of the livestock, and place of slaughter) cannot be achieved through a labelling requirement that denotes origin? How else can it be achieved? Had it examined the measure under Article 2.2 TBT, then the $\mathrm{AB}$ might have been in position to point to at least one other less restrictive option.

15 Irwin (1998). 


\subsection{Brief recap of the major points}

The $\mathrm{AB}$ reached its conclusions under Article 2.1 TBT inappropriately so with respect to some of them: the quantum of information requested relative to that which is disseminated is not an issue that can conceivably come under Article 2.1 TBT, unless the discrepancy is origin based. This has not been the case in this dispute. The remaining findings suffer as well: the affidavits submitted do not discuss at all the question of attribution of the detrimental (trade) impact to the COOL measure; the relevance of some of the econometric evidence submitted was reduced by the Panel itself, and, with respect to the rest, the question asked does not suffice to support a finding that discrimination has indeed been afforded.

The treatment of econometric evidence by both the Panel and the AB leaves a lot to be desired. It is quite remarkable that Panels refuse to make use of Article 13 DSU, and invite economists and econometricians to testify before it, and appraise submitted evidence. It is counter-productive to hide behind 'in house-expertise' in this area. WTO staff members that have the appropriate economics training scarcely appear before Panels and the $\mathrm{AB}$, and they do not have to sign the opinions that they defend. Invited experts will have to bear the full reputational cost of their opinions, and this, on occasion, could provide them with a dis-incentive to take the whole exercise 'light-heartedly'.

\section{Concluding remarks}

In what preceded, we have argued that the $\mathrm{AB}$ should not have reached the outcome it did based on the information before it, and that, ideally, it should have applied a different methodology as well. The $\mathrm{AB}$ applied the wrong methodology and also reached the wrong conclusion: the $\mathrm{AB}$ ruled that US-COOL was discriminatory but made no finding regarding its necessity. Thus, US-COOL could have been necessary to achieve a legitimate objective.

In our view, the $\mathrm{AB}$ essentially threw its hands up in the air on the most critical question to emerge from this case: was the COOL measure more restrictive than necessary to meet the legitimate objective of providing consumers with more information? By choosing to not 'complete the legal analysis under Article 2.2. of the TBT' due to the 'lack of sufficient undisputed facts on the Panel record', the AB missed an opportunity to set an important precedent. If US-COOL was indeed more trade restrictive than necessary, what should take its place? And, as the AB correctly noted, complainants had not met the burden of proof regarding the existence of any such alternative measure. ${ }^{16}$ For example, Canada and Mexico had

16 Three types of alternative measures were discussed: (i) a market driven voluntary labelling scheme; (ii) a mandatory labelling scheme based on substantial transformation (i.e. slaughter); and (iii) a trace back scheme under which a retailer could trace back the precise location of each processing step (farm, feedlot, 
argued that market-driven 'voluntary labelling' in the US meat market would be less trade-restrictive since 'segregation costs would be borne only by those livestock producers catering to interested consumers'. But such conclusions are not straightforward in the presence of asymmetric and incomplete information in the product market.

In our view, the lack of widespread voluntary or market-based labelling prior to $U S-C O O L$ is certainly not sufficient to conclude that US-COOL was more trade restrictive than necessary. After all, even if such voluntary labelling was pervasive, would regulation ensuring its accuracy not be necessary? And isn't the credibility of private labelling enhanced when it is backed by supporting government regulations that are properly enforced? Furthermore, for voluntary labelling to be less confusing to consumers than US-COOL, the industry would need to converge to some sort of a common standard as opposed to each retailer choosing its own approach. Of course, this brings us back full circle to the question confronting the US government: what type of labelling scheme can convey accurate information to consumers about the origin of meat products while restricting trade as little as possible? Without answering this key question, it is hard to see how the AB ruled the way that it did.

\section{Post-scriptum}

In May 2013, the US announced the specific actions it had undertaken in order to comply with the $\mathrm{AB}$ rulings and recommendations (Federal Register, vol. 78, No 101, Friday 24 May, 2013, pp. 31367ff.). It summarized its compliance activities in the following terms:

Under this final rule, origin designations for muscle cut covered commodities derived from animals slaughtered in the United States are required to specify the production steps of birth, raising, and slaughter of the animal from which the meat is derived that took place in each country listed on the origin designation. In addition, this rule eliminates the allowance for commingling of muscle cut covered commodities of different origins. These changes will provide consumers with more specific information about the origin of muscle cut covered commodities.

The US estimated that the loss of the commingling flexibility would entail costs rising at $\$ 7.16$ per head for cattle, and $\$ 1.79$ per head of hogs currently commingled at the packer/processor level. Estimated costs at the retail level are $\$ 0.050$ per pound of beef, and $\$ 0.045$ per pound of pork muscle cuts currently

processing facility' for every piece of meat. The first scheme would provide highly incomplete coverage of the market (much less than under COOL); the second would simply not meet the objective of providing adequate information regarding origin; while the third would be significantly costlier to implement than the COOL measure. 
commingled. Estimated total costs, because of the loss of the commingling flexibility for the beef segment, would be $\$ 21.1$ million, $\$ 52.8$ million, and $\$ 84.5$ million at the lower, mid-point, and upper levels respectively. The corresponding figures for the pork market would be $\$ 15.0$ million, $\$ 37.7$ million, and $\$ 60.3$ million. The inescapable conclusion is that because of the compliance activity, consumers would eventually be burdened with higher prices for beef and pork meat.

A combination of the costs for label changes as well as those resulting from the loss of the commingling flexibility would yield in the eyes of the US total adjustment costs of $\$ 123.3$ million at the mid-point (the range spanning from $\$ 53.1$ to $\$ 192.1$ million). Note also that 'The [US] Agency believes that the incremental benefits from the labelling of production steps will be comparatively small relative to those that were discussed in the 2009 final rule.'

In the eyes of the US authorities thus, all this amounts more or less to 'much ado about nothing'. Recall that, although the AB had found that the US measure had been requesting from traders more information than what the law eventually revealed, it did not find that the US measure had failed the necessity-requirement embedded in Article 2.2 TBT.

\section{References}

Baldwin, R. E. (1970), Non-Tariff Distortions in International Trade, Washington, DC: Brookings Institution.

Horn, H., L. Johannesson, and P. C. Mavroidis (2011), 'The WTO Dispute Settlement System: 1995-2010, Some Descriptive Statistics', Journal of World Trade, 45: 1107-1138.

Horn, H. and J. H. H. Weiler (2007), 'EC-Trade Description of Sardines: Textualism and Its Discontent', in H. Horn and P. C. Mavroidis (eds.), The WTO Case Law of 2001-2003, the American Law Institute Reporters' Studies, Cambridge: Cambridge University Press, pp. 551-578.

Howse, R. and P. Levy (2012), 'The TBT Panels: US-Clove Cigarettes, US-Tuna, and US-COOL', The World Trade Review, 12: 327-376.

Irwin, D. A. (1998), 'Changes in US Tariffs: The Role of Import Prices and Commercial Policies', The American Economic Review, 88: 1015-1026.

Irwin, D. A., P. C. Mavroidis, and A. O. Sykes (2008), The Genesis of the GATT, Cambridge: Cambridge University Press.

Jurenas, R. and J. L. Greene (2013), Country of Origin Labelling for Foods and the WTO Dispute on Meat Labelling, Congressional Research Service.

Mavroidis, P. C. (2013), 'Driftin' Too Far from Shore: Why the Test for Compliance with the TBT Agreement Developed by the WTO Appellate Body is Wrong, and what Should the Appellate Body Have Done Instead', The World Trade Review, 12(3): 509-531. 